\title{
Title: Fostering EfS connections for community wellbeing: Working meaningfully with what we've got
}

\author{
Sherridan Emery (PhD Candidate) \\ Faculty of Education \\ University of Tasmania \\ Tasmania, Australia Email: sherridan.emery@utas.edu.au \\ Kim Beasy (PhD Candidate) \\ Faculty of Education \\ University of Tasmania \\ Tasmania, Australia \\ Email:kim.beasy@utas.edu.au \\ Bianca Coleman (PhD Candidate) \\ Faculty of Education \\ University of Tasmania \\ Tasmania, Australia \\ Email: bianca.coleman@utas.edu.au
}

\section{Abstract}

The Sustainable Development Goals compel universities to engage in locally relevant Education for Sustainability (EfS) partnerships with communities. In Tasmania, studentresearchers in education are engaging with schools to support sustainability collaborations in communities. This paper showcases a collaborative community platform that has enabled EfS projects to be co-delivered by the University and local community partners. We theorise the student-researcher community interactions from two case studies and offer insights into the ways that student-researchers employ cultural capital in efforts to build local momentum for EfS and enhance community wellbeing.

The first case study explores a student-researcher's entanglements with a school's cultural arts class which took its weekly rug-making sessions into the local community centre. Students taught others how to latch hook a rug, positioning students in a different light - as cultural producers and contributors to their community.

The second case study investigates a student-researcher led community engagement event, 'Don't Mess With Burnie', which was designed to involve students in taking action to address marine litter. Activities included a beach clean up, explorations of the water cycle, and found-object art. Through this event school students were empowered to make a difference to the local beach foreshore where they play. 
Through a discussion of student-researcher cultural capital, this paper offers theoretical insights into the 'living laboratory possibilities' of university research and community collaborations more generally 


\section{Introduction}

In recent decades, there has been increasing pressure for universities to take an active role in engaging with contemporary issues of local and global scales and become immersed in the world (Berman, 2008). The Sustainable Development Goals (SDGs), further compel action, in particular Target 4.7 states;

By 2030, ensure that all learners acquire the knowledge and skills needed to promote sustainable development, including, among others, through education for sustainable development and sustainable lifestyles, human rights, gender equality, promotion of a culture of peace and non-violence, global citizenship and appreciation of cultural diversity and of culture's contribution to sustainable development (United Nations, 2018)

Student-researchers (ie. $\mathrm{PhD}$ candidates) form a sector of the university population which is growing in size and which provides much unleashed potential for supporting universities in addressing SDGs. Yet in this chapter, we argue that student researchers are a largely overlooked group contributing to actions for sustainability.

Part of the contribution this chapter makes is to challenge deficit discourses of SRs which we argue limits their imaginaries of what they can contribute as change agents. We call instead for strength based views which help to realise the potential of SRs as change agents in light of the growing population of SRs in universities globally.

We report on two cases within one university setting (the University of Tasmania) in which SRs led initiatives to engage communities in projects centered around cultural, environmental and social sustainability. These examples showcase the potentiality of SRs as active agents in facilitating action for sustainability. The SRs in these case studies were entangled with a network of engaged sustainability educators through Education for Sustainability Tasmania (EfSTas) (a United Nations University Recognised Regional Centre of Expertise in Education for Sustainable Development), which served a linking and leveraging role in which SR capitals could be realised. While the SRs' $\mathrm{PhD}$ projects were discrete research projects within the Education Faculty of the University of Tasmania, they were also interwoven with EfSTas as this chapter explains.

To offer some context, Tasmania is an island state of Australia, with a rich cultural and natural heritage, including high biodiversity, abundant fertile soil, water, clear air and renewable energy (hydroelectricity) (Australian Bureau of Statistics [ABS], 2006). In addition, Tasmania faces distinctive sustainability challenges associated with remoteness, a weak economy relative to mainland Australia, a historical reliance on exploitative activities (e.g., old growth forest logging, damming and mining), high levels of socioeconomic disadvantage and a low and aging population (ABS, 2006). Tasmania's social and political environment makes the state a rich area for experimenting with practice models in the delivery of sustainability education. 
In the first section of this chapter, we discuss the role of EfSTas for the connectivity of sustainability education in Tasmania and the legitimacy it provides for new projects and initiatives. In subsequent sections, we detail the two case studies, one based on a cultural arts program in a school and the other on an environmental awareness raising initiative. We offer insights into the ways that SRs employ cultural capital to build local momentum for EfS. Drawing upon Bourdieu's (1986) theoretical lens of cultural capital, we develop insights into how SRs can propel agendas of sustainability in local communities. Finally, we explore how the SRs' entanglements with EfSTas opened up powerful opportunities for the SRs to activate and enact their cultural capital in ways which enhance community wellbeing.

\section{Education For Sustainability Tasmania: A Regional Centre of Expertise - A Complex Entanglement}

EfSTas is a recently recognised Regional Centre of Expertise on Education for Sustainable Development (UNRCE), and here we attempt to make explicit some of the complex entanglements which characterise this network and enables the types of opportunities outlined in the case studies (United Nations University, n.d.). Specifically within this account, we focus on the role of SRs in the EfSTas network, while at the same time exploring the dialectic of SRs and community activities using the two case studies.

EfSTas is a collaborative network that brings together the strengths of existing individuals and organisations within Tasmania currently working towards addressing challenges linked to environmental, economic and sociocultural sustainability. Under the UNRCE umbrella, Tasmania is conceptualised as a living laboratory to explore ways to work towards sustainability, with education as a central tool. The vision of EfSTas is to advance Tasmania as an interconnected and diverse sustainable island state that is able to adapt and respond to environmental, economic, social and cultural challenges. EfSTas aims to help overcome the sustainability challenges faced by the region, to create a healthier, environmentally and culturally sustainable, and more equitable Tasmanian community. In so doing, EfSTas makes a significant contribution to the global learning space for EfS as an experimental test bed to explore new models of sustainability principles and practice.

The entanglement of EfSTas is made possible by members contributing to mutually beneficial projects under the auspices of EfSTas. The case studies introduced in the next section are indicative of the types of projects facilitated through connections within EfSTas.

\section{Methodology}

We use case studies (Denzin \& Lincoln, 1994) as a means of exploring the entangled relations of SRs in communities and in particular to focus on the activation of SR cultural capital. We locate our theoretical positioning as valuing multiple knowledges, drawing on the concept of 'an ecology of knowledges' (De Sousa Santos, 2007) to value the "epistemological diversity of the world, the recognition of the existence of a plurality of 
knowledges, beyond scientific knowledge" (p. 67). We contend that De Sousa Santos' call for valuing of diversity encourages activities where the local matters. We advance this perspective in our interpretation of SDG 4.7's intention that "all learners acquire the knowledge and skills needed to promote sustainable development" (United Nations, 2018). One of the knowledges we focus on (particularly in the cultural arts class study) is that of children's participation in education for sustainability through cultural production (Kuttner, 2015). Cultural production is connected with cultural citizenship, which Kuttner describes as 'the right and capacity of people to develop and pass on diverse cultural traditions and identities while participating effectively in a shared cultural and political arena' (p.70).

\section{Case study 1: Weaving community wellbeing in the cultural arts class}

The first case study explores the entanglements of a SR (a co-author of this chapter (SE)) with a regional government school's cultural arts class for year 4-6 students. These entanglements included an initiative in which students shared a cultural practice within their community and an event in which the school students were extended an opportunity to share their culture in a professional forum through EfSTas.

\section{Weaving the community rug (storying cultural experiences as curriculum)}

One of the projects the cultural arts class engaged in over the course of a term was the making of a community rug. The cultural arts program educators, Kathryn and Valerie (pseudonyms are used), made the decision to conduct the weekly cultural arts class sessions in the local community centre. The educators chose to design the rug with inspiration from the patterns of the Preminganah petroglyphs which are significant to Tasmanian Aboriginal people, and the colours of the décor in the community centre at the heart of the students' town.

Each week the students worked on the rug alongside other community members in the community centre. The students taught members of the community skills of latch hooking and felting so that everyone together could contribute to the creation of the rug. This positioned students in a new light, as cultural producers and contributors to their community. A reflective memo written by the SR (SE) after a school morning spent with the cultural arts class is included below:

27/9/2015: We sat around the timber table at the local community centre making a community rug. Five students, a student networker, an Aboriginal artist, a university researcher, and some community centre employees sat together in a circle, latch hooking small knots in a piece of hessian with brightly coloured acrylic wool. Working their latch hooks through the hessian to form each knot, the students created the outlines of the circles that are key features of the Preminganah petroglyphs, which were etched into the large rocks on the west coast of Tasmania long ago by Aboriginal people. Over the ensuing month of visits, family members and community centre employees and visitors became part of the rugmaking circle, transforming the sheet of brown hessian and acrylic wool into the beginnings of a beautiful colourful rug. 
There was an easy conversation that flowed around the table while everyone worked on their respective section of the rug. Some people worked together in pairs. One student showed her mother how to work the felting needle over a felted section of the rug. Students with better latch hooking skills taught people with less developed skills (like me) how to form the knots most efficiently. At the same time, around us mothers (and some fathers) with young children arrived at the centre and children ran off to play in the various play spaces. I noticed that making the rug seemed to create an intentional space which was safe and in which conversations could occur with ease. [Social sustainability - community wellbeing]

This rug-making unit was an arts project designed by the educators to support cultural sustainability. During the SR's participation in the cultural arts program, she supported the educators to connect their program to the Australian Curriculum in the arts, which added 'curricular legitimacy' to this program. The explicit teaching of arts skills and knowledge was part of the program's curriculum, but within a broader frame of cultural wellbeing [which was the student researcher's doctoral study topic], the program was not simply about content and pedagogy. There was intentional skill development being taught: creating the rug provided the structure for developing an array of art skills including knotting (shag and loop pile) and felting techniques. These skills linked with the making and presenting aspects of the Arts curriculum and the fibres strand of the Design and Technologies curriculum (Australian Curriculum Assessment and Reporting Authority, n.d.). Students also acquired historical and geographic knowledge about the history of Tasmanian Aboriginal people and the Preminganah petroglyphs on the west coast.

Importantly from a wellbeing perspective, social and emotional learning was supported through rug making at the community centre, through students' engaging with family and community members. Strengthening students' connections to community was an area in which the student networker and artist had identified as a priority for cultural sustainability. With the rug making project, students had opportunities for social interaction and meeting people as they worked on the rug alongside members of their community. In this project students were positioned on an equal footing with other members of the community, positioned as artists teaching other family members and community members how to latch hook and how to felt. Through this cultural arts project, students were given the platform to be visible and active contributors to their community.

\section{Children leading the sharing of culture}

During the SR's entanglements with the cultural arts group, the opportunity surfaced to invite the students into a statewide professional learning forum as presenters and cultural leaders.

At the EfS Tasmania professional forum in October 2017 the students from the school travelled to Launceston at the invitation of EfSTas to co-present a workshop for Tasmanian educators. The students began by delivering an Acknowledgement of Country in palawa-kani, "the revived form of the original Tasmanian Aboriginal languages" 
(http://tacinc.com.au/programs/palawa-kani/). The Acknowledgement is an important custom of showing respect to Aboriginal Elders past and present and honoring that a gathering is taking place on land which Aboriginal people never ceded and of which Aboriginal people have been custodians for millennia.

During the workshop the school students also led participants in a workshop activity of learning how to make string, sharing the technique they had learned through the cultural arts program using dried and softened river reeds. String making is one of the enduring crafts of Tasmanian Aboriginal peoples in Tasmania (and Australia more widely). Through this initiative of inviting students to present the Acknowledgement of Country and a skills workshop for teachers, the school students were recognized as cultural citizens, continuing the traditions and practices of Tasmanian Aboriginal peoples in a contemporary gathering. This can be viewed as a practice of decolonizing curriculum and reinhabitation of Aboriginal culture in education (Lincoln \& González y González, 2008).

\section{Case Study 2: Partnerships in community-based environmental sustainability education}

The second case study details a community engagement event, 'Don't Mess with Burnie' (DMWB), which was led by two SRs who are co-authors of this chapter (KB and BC). This event was designed to involve children in taking action to address local environmental concerns, including marine debris, pest and problem animal control and recycling and waste management. The Don't Mess with Burnie activities were conducted over a full-school day and involved over 300 primary school children (aged 8-11 years) and their teachers, included a beach clean-up, found object art, participation in science experiments and tours of local waste management facilities. Through this event, school students were empowered to make a difference to the local beach foreshore where they play and to their regional community more generally. Likewise, the hands-on activities also provided professional learning opportunities for teachers. Teachers were able to engage with these activities alongside their students and they discovered how environmental and sustainability education could be meaningfully achieved in their own classroom contexts and local community.

\section{Burnie as site for 'Don't Mess With Burnie'}

The opportunity for the SRs to facilitate a community engagement event in collaboration with the state government department of education, arose when their university offered small-grant funding to promote and encourage connections between the university and schools. The SRs, both having a particular interest in sustainability and environmental education, planned a community-based environmental education project for primary school-aged children in Tasmania's North West city of Burnie (approximately 20,000 people). The SRs were successful in their bid for grant-funding, obtaining approximately AUD \$1800 to facilitate the project and to pay for students' transportation to the event. This funding allocation exceeded the SRs initial request, with the University acknowledging the immense value of the event and its role in contributing to an environmentally sustainable future in Tasmania. 
Burnie is an area of high socio-economic disadvantage with one of the highest rates of youth unemployment in Australia (Australian Bureau of Statistics, 2016). For this reason, the SRs purposefully selected this region of Tasmania to host the event and the schools that participated were those from areas with particularly high levels of disadvantage as measured by their below national-average Index of Community Socio-Educational Advantage (ICSEA) rating, a nationally recognised measure of community social and educational indicators. In addition to the provision of educational opportunities in Burnie, the SRs understood that issues related to the environment and sustainability are of particular relevance to this region. The region's economy strongly relies on agriculture, forestry, manufacturing, mining and tourism (Brindley \& Turner, 2015). Conservation and effective sustainable management of the environment, therefore, is critical to the ongoing economic prosperity of the region. The event aimed to highlight the roles of individuals, businesses, and the university in ensuring the sustainable use of the region's environmental resources. DMWB was designed to speak to the often-conflicting discourses students in this region are exposed to; that is, economic progress vs. environmental protection, job creation vs. job loss (Stratford, Armstrong \& Jaskolski, 2003). Additionally, as the event was scheduled during Australia's National Recycling Week, the 'reduce-reuse-recycle' message was at the heart of the day's activities.

\section{University, school and community partnerships}

The SRs were particularly motivated to develop positive partnerships between the University, the Tasmanian Department of Education and its schools, local community members and private industry to ensure the ongoing sustainability of the event. Through their affiliation with the University and connection with EfSTas, the SRs were able to connect with a number of enthusiastic classroom teachers and industry professionals who freely offered their knowledge, time and expertise in supporting students to develop their understanding of environmental sustainability. While much of the logistics of the event (e.g. physical space, transportation, organising facilitators, advertising and promotion, liaising with school staff) were organised by the SRs, the successful outcomes of the event were achieved through the collaborative efforts of the SRs, teachers, community members and industry professionals.

To establish these partnerships, the SRs organised a number of web-conferences that brought facilitators and participating teachers together prior to the event. These web-conferences provided opportunities for the teachers to ask questions of the SRs and facilitating community members and industry professionals about how the day would run and the activities/topics that would be covered to help them prepare their students and to plan relevant pre-and-post event classroom-based learning activities.

\section{Environmental sustainability learning in action}

The DMWB event began with an opening address from a Burnie City Council representative which underscored the importance of environmental sustainability initiatives in north-west Tasmania and acknowledged the Plairhekehillerplue People, the traditional Aboriginal owners and custodians of the lands on which Burnie is located and whom for generations 
have protected, nurtured and sustained its environment. Students then dispersed to participate in a wide variety of participatory environmental sustainability activities through which different classes of students rotated throughout the day. These activities included:

Beach clean-up: West Beach in Burnie is situated approximately 300 metres from the city's central business district. It connects the city's main retail and shopping facilities with one of its most popular tourist attractions via a boardwalk built above the foreshore. West Beach is host to a penguin habitat and is a popular beach for swimming and other recreational activities. Pollution, in the form of litter from neighbouring food retailers, assorted plastics and abandoned fishing tackle, is a critical issue at this beach. The beach clean-up activity involved students collectively and systematically scanning a section of the beach, removing rubbish and marine debris, and cataloguing the types of debris that were found and its origins. Through this activity, the students were actively engaged in thinking about and evaluating their community's impact on the coastal environment while undertaking meaningful and achievable action to address the problem. Having cleared a section of the beach of visible litter and debris, students further engaged in discussions with the activity facilitator (a representative from the Tasmanian Department of Education organised by the SRs) about appropriate waste management strategies, recycling, single-use plastics and the impact of marine debris on marine and bird life.

Swap meet: A flea-market style 'swap meet' in which students swapped items such as toys, books and clothing was also organised to enhance and extend students' understanding of the 'reduce-reuse-recycle' message. In exchange for tokens (gumnuts, wooded fruits from the Australian Eucalyptus tree), students brought items from home that they no longer played with or used to share with their peers. At lunch-time and between other activities, the SRs and other facilitators supported students to visit the swap meet to exchange their tokens for the pre-owned items shared by their peers. The swap meet was highly effective in enabling students to see the value of pre-owned toys, books and clothing and in encouraging them to consider more sustainable ways of managing their no-longer needed possessions. The impact of this learning on students' perceptions of pre-owned products is perhaps best highlighted by one school's commitment to undertaking their own regular swap meet activity at school.

Kids teaching kids: The philosophy for this event was underpinned by a belief that a participatory, student-led approach is the most effective and meaningful way for young people to learn about environmental sustainability (De Sousa Santos, 2007; de Vreede, C., Warner, \& Pitter, 2014; Jensen \& Schnack, 1997). As such, it was a key priority of the event to enable and encourage students to take responsibility for educating their peers about ways that they can adopt a more sustainable approach to their lives. One of the SRs worked closely with a local primary school to support a class of students to prepare a number of short handson activities addressing environmental sustainability in their schools. These activities included rubbish and recycling sorting and designing a plastic-free lunch box. These activities not only gave those students who delivered the activities a sense of agency over their learning and leadership in environmental sustainability but enabled their audience of peers to envision ways in which they too can live a more sustainable life. 


\section{Discussion: Through the lens of Cultural Capital}

In this section, we consider the living laboratory possibilities of SRs through the case studies detailed above. We think with Bourdieu's concept of cultural capital as one way of exploring how SRs have valuable contributions to make to broader objectives for sustainable development in local communities. Through this, we hope to draw attention to the potentiality of SRs as agents of change in their communities through their research projects and skill sets. This is a different view to discourses of SRs as needy novice and/or neophyte researchers which are views conveyed in discourses of postgraduate research (Natalier, 2011). It offers a more powerful and agentic view of SRs as active in the shaping of their communities. Before moving into the discussion, we offer a brief description of cultural capital (Bourdieu, 1986).

\section{Cultural Capital - What is it?}

Cultural capital consists of social assets that are held or embodied in people. Bourdieu (1986) distinguishes between three forms of cultural capital: embodied in people in the form of knowledge or skills; the objectified state, such as cultural goods, e.g., books, art pieces; and in the institutionalised state such as educational qualifications. Embodied cultural capital requires an investment in time by the person and refers to people's values, skills, knowledge and tastes. Similarly, objectified cultural capital requires access to the embodied cultural capital to use particular objects for their specific purpose, e.g., such as owning a bicycle (objectified capital) but requiring the embodied cultural capital to ride it. Bourdieu's concept of institutionalised cultural capital refers to educational attainment and qualifications and can be viewed as the objective of school settings.

\section{Reciprocal relations between community and SRs}

Working in the community provides a tangible application of student researcher skills in the midst of lengthy individual $\mathrm{PhD}$ research projects that are often isolating and abstracted from 'the real-world'. Research suggests that when SRs are engaged in meaningful activities that are related to their research in some way, they are more engaged with their studies and have better wellbeing (Baker \& Latucca, 2010; Pyhältö, \& Keskinen, 2012). To see theory in practice, and to see your research used and applied in the community is an empowering experience which helps to fuel the momentum for continuing on a PhD journey (Pyhältö, \& Keskinen, 2012).

The DMWB event provided an opportunity for SRs to apply their theoretical knowledge of sustainability engagement in a tangible and practically relevant way. The event was strongly connected with both SRs' research areas and was an opportunity to see how theoretical ideas 'play out' in real time and space, such as children's interpretations of what sustainability means. The event also acted to galvanise SR relationships with key practitioners in their 
discipline field, such as participating teachers and community organisations delivering environmental sustainability workshops on the day.

It was through SRs' combined cultural capital that they were able to facilitate the event. One SR had previous experience as a school teacher, which meant they had an intimate understanding of what is required for teachers to participate in all-day off-site excursions (e.g. forms, procedures). The other SR had a work history in environmental behaviour change engagement which formed a key asset in constructing the program of the day. In addition, because the SRs were a part of the University, they were eligible to apply for funding to support the event. The SRs provided access to the grant and the skills and expertise in the development of the application, which was successful.

Similarly, the partnership between the SR and the cultural arts educator and students provided opportunities for enhancing cultural capital for all partners involved. The activation of cultural capitals between the SR and the cultural arts educators and students was encompassed within the beneficial relationship which educators perceived as supporting students' cultural wellbeing.

In this exchange, the cultural arts class provided a tangible location for exploring the concept of cultural wellbeing and considering ways in which Aboriginal culture and broader concepts of culture interacted with cultural wellbeing (the focus of the SR's research). In return the SR offered to the cultural arts class a sounding board; assistance with connecting the enacted curriculum in the class to the ACARA curriculum; opportunities for students in the cultural arts class to exercise their leadership in the community through teaching others valued cultural practices which we argue enhances community wellbeing.

EfSTas afforded the research partnership opportunities for the SR to extend such leadership opportunities outlined above to the cultural arts educators and students. The cultural arts program was designed to enhance Aboriginal students' pride in their culture and their social and emotional wellbeing. Opportunities to present their culture to audiences for occasions including the EfS Tasmania professional forum provided authentic occasions for the cultural arts students to share their achievements and the skills they had developed.

The SR's entanglement with EfSTas afforded the opportunity to invite students from the cultural arts class to teach teachers about their aboriginal culture, on their terms, in a statewide professional learning forum. This opportunity for school students to share the experiences and skills they had developed in the cultural arts class was one which the SR could not have created on her own. It came about through the SR's entanglement with EfSTas and was brought into being through the opening made available through EfSTas for the SR to share her research into cultural wellbeing in the EfS Tasmania professional forum.

One aspect of this entangled relation of EfSTas which made this possible was the geographically distributed nature of the statewide forums. The forums travelled around to three main cities/towns in Tasmania. If the EfSTas professional forum occurred only in the 
capital city (as often tends to happen), the access to local knowledges would have been more restricted. The cultural arts group could travel to Launceston to share their learning, but logistically and financially, it would have been prohibitive for the group to travel to Hobart. The distribution of events across the state embodies de Sousa Santos' (2007) call for ecologies of knowledges that value the local.

In a similar way, the DMWB event was made possible through the relations within the EfSTas network of people. One SR is an active committee member which puts her in contact with key stakeholders delivering sustainability education in Tasmania. It was only through conversation with the Department of Education representative that the idea of having the event was formed. In addition, the network of EfSTas people acted as a perceived safety-net for the SRs during the organisation of the event. The relationships and combined knowledges of the network made planning the event (including who would be involved in delivering workshops) an easy process. Without this network of support, the SRs would not have taken on lead organising or facilitating roles.

A common feature in both case studies is that local people, local values and local needs were at the centre of the initiatives. We argue that not only does the local matter, but that the locals who make up 'the local' matter.

\section{Conclusion}

EfSTas promotes itself as a living laboratory, building upon Tasmania's distinction as an island state that is a part of Australia, yet set apart from Australia. As a living laboratory, EfSTas is crafting an approach to sustainability education in Tasmania that embraces student researcher community collaboration. As this chapter shows, SRs are working hand in hand with Tasmanian communities to activate their own cultural capital and to enhance that of the community members with whom they work, to provide platforms for localised social change on sustainability issues and enter into SDG discourses in Australia.

The case studies outlined in this chapter illustrate the potential that SRs offer as an underrealised asset for communities. We suggest that when SRs are provided with the right kinds of enabling platforms, they are able to extend the benefit of their research and growing cultural capital within the community. Through its events and activities, EfSTas is one such enabling platform that affords student researchers a forum for bringing their studentresearcher cultural capital into contact with the community. The experiences of SRs and community working and learning together demonstrate the reciprocity of partnerships that galvanise around SDGs.

Finally, we have written this paper as a means of contributing to discourses of sustainability in higher education, to offer examples of how collaborations led by SRs can bring together academic and local expertise to create educative moments that contribute toward sustainable development. SDG 4.7 calls for ensuring that all learners "acquire the knowledge and skills to promote sustainable development". We have shown how local knowledges and skills have 
been at the forefront of the progress being made by a newly recognised Regional Centre of Expertise in Education for Sustainable Development. It is hoped that this chapter inspires new ways of considering how student researchers can be agents of change in university contributions towards SDG.

\section{References}

Australian Bureau of Statistics [ABS]. (2006). 1362.6 - Regional Statistics, Tasmania, 2007. Retrieved from http://www.abs.gov.au/ausstats/abs@.nsf/mf/1362.6

Australian Bureau of Statistics [ABS]. (2016). 2016 Census QuickStats - Burnie. Retrieved from http://www.censusdata.abs.gov.au/census_services/getproduct/census/2016/quickstat/L GA60610

Australian Curriculum Assessment and Reporting Authority, (n.d.). F-10 Curriculum, Retrieved from https://www.australiancurriculum.edu.au/f-10-curriculum/

Baker, V. \& Lattuca, L. (2010). Developmental networks and learning: toward an interdisciplinary perspective on identity development during doctoral study. Studies in Higher Education, 35(7), 807-827, DOI: 10.1080/03075070903501887

Berman, J. (2008) Connecting with industry: bridging the divide, Journal of Higher Education Policy and Management, 30(2), 165-174, DOI: 10.1080/13600800801938762

Bourdieu, P. (1986). The forms of capital. In J. E. Richardson, Handbook of theory of research for the sociology of education (pp. 46-58). Westport, United States: Greenwood Press.

Brindley, M., \& Turner, K. (2015). The future role and contribution of regional capitals to Australia: A Tasmanian perspective. Launceston, TAS: Regional Development Australia - Tasmania.

De Sousa Santos, B. (2007). Beyond Abyssal Thinking: From Global Lines to Ecologies of Knowledges. Review (Fernand Braudel Center), 30(1), 45-89. Retrieved from http://www.jstor.org/stable/40241677

De Vreede, C., Warner, A., \& Pitter, R. (2014). Facilitating youth to take sustainability actions: The potential of peer education. The Journal of Environmental Education, 45(1), 37-56.

Denzin, N. K., \& Lincoln, Y. S. (Eds.). (1994). Handbook of qualitative research. Thousand Oaks, CA, US: Sage Publications, Inc. 
Jensen, B. B., \& Schnack, K. (1997). The action competence approach in environmental education. Environmental education research, 3(2), 163-178.

Kuttner, P. J. (2015). Educating for cultural citizenship: Reframing the goals of arts education. Curriculum Inquiry, 45(1), 69-92.

Lincoln, Y. S., \& González y González, E. M. (2008). The search for emerging decolonizing methodologies in qualitative research: Further strategies for liberatory and democratic inquiry. Qualitative Inquiry, 14(5), 784-805.

Natalier, K. (2011). Treat your supervisor right! The Thesis Whisperer. Retrieved from https://thesiswhisperer.com/2011/09/22/treat-your-supervisor-right/

Pyhältö, K., \& Keskinen, J. (2012). Doctoral Students' Sense of Relational Agency in Their Scholarly Communities. International Journal of Higher Education, 1(2), 136-149. Retrieved from https://files.eric.ed.gov/fulltext/EJ1057243.pdf

Stratford, E., Armstrong, D., \& Jaskolski, M. (2003). Relational spaces and the geopolitics of community participation in two Tasmanian local governments: A case for agonistic pluralism? Transactions of the Institute of British Geographers, 28(4), 461-472. doi: $10.2307 / 3804392$

United Nations. (2018, February). SDG Indicators. Retrieved from https://unstats.un.org/sdgs/metadata/

United Nations University. (n.d.). Global RCE Network Education for Sustainable Development. Retrieved from http://www.rcenetwork.org/portal/ 